\title{
Vowel Nasalisation in Scottish Gaelic: The Search for Paradigm Uniformity Effects in Fine-Grained Phonetic Detail
}

\author{
Donald Alasdair Morrison \\ The University of Manchester
}

\section{Introduction}

According to the modular feedforward architecture of grammar, the phonetics is a separate module ordered after the phonology and is sensitive only to the output of the latter (Pierrehumbert 2002). It follows that the phonetics should be blind to morphological factors, but this prediction has been challenged by claims that fine-grained phonetic detail may be subject to paradigm uniformity effects (e.g. Steriade 2000). In a nasal airflow study of a speaker of Scottish Gaelic, I identify both phonetic and phonological patterns of vowel nasalisation and demonstrate that only phonological nasalisation is subject to morphological conditioning. These findings are exactly in line with the predictions of a modular architecture.

In §2 I will explore the theoretical and analytical issues surrounding apparent phonetic paradigm uniformity effects and show that some putative instances can in fact be accounted for under a modular architecture. In §3 I will introduce some aspects of the Scottish Gaelic sound system that will be relevant to this study. The methods used in the study will be outlined in $\S 4$ and the results presented and discussed in $\S 5$.

\section{Background}

2.1 Phonology vs. phonetics According to a widespread view (e.g. Keating 1996: 263), the main distinction between phonology and phonetics is that the former acts upon discrete, categorical representations while the latter translates the output of the phonology into the gradient, continuous articulatory and auditory dimensions that constitute spoken language. It follows that categorical sound patterns should be assigned to the phonology and gradient sound patterns to the phonetics.

Categoricity can manifest itself in two ways. On the one hand, a process can be claimed to be categorical if it leads to a bimodal distribution of tokens along some dimension, such as duration or F2 in vowels (for discussion, see Scobbie 2005: 13, Bermúdez-Otero \& Trousdale 2012: 696). On the other hand, a process that raises $\mathrm{F} 2$ in vowels before some consonant $\mathrm{C}$ may be taken to be categorical if $\mathrm{F} 2$ is raised throughout the duration of the vowel, and gradient if F2 only begins to rise during the later part of the vowel on the approach to C. Since this study is concerned with patterns of nasal airflow, I will define categoricity and gradience in a manner going back to Cohn (1990), who investigated phonological and phonetic patterns of nasal airflow in several languages including English.

As discussed in Cohn (1990), a vowel that is nasalised in the categorical phonological representation will display a plateau-like pattern of nasal airflow, so that nasal airflow is sustained at a high level throughout the duration of the vowel. On the other hand, a vowel that is nasalised by a phonetic process of co-articulation with an immediately preceding nasal consonant will display a cline-like pattern, meaning that nasal airflow appears only early in the vowel and declines to zero part of the way through its duration. In \$5 I will use these criteria to identify categoricity and gradience in nasalised vowels in Scottish Gaelic.

\footnotetext{
* I am grateful to Ricardo Bermúdez-Otero, Wendell Kimper and Claire Nance for their invaluable help and feedback, and to audiences and anonymous reviewers at the 25th Manchester Phonology Meeting, the 2017 annual meeting of the Linguistics Association of Great Britain, the 5th Annual Meeting on Phonology and the 15th Old World Conference on Phonology for their helpful comments. This work was supported by the Economic and Social Research Council [grant number ES/J500094/1].
}

(C) 2018 Donald Alasdair Morrison

Proceedings of AMP 2017 
2.2 Paradigm uniformity effects It has often been observed that the ordinary application of phonological processes may be overridden by a tendency towards uniformity within morphological paradigms. For instance, most dialects of English display a process whereby a place-assimilated nasal causes deletion of a following /g/ in the coda, e.g. si/Ng/ $>$ si $/ \mathrm{g} /$, but not in the onset, e.g. fi/Ng/er $>$ fi/gg/er. This process overapplies in suffixed forms in which stem-final /g/ would be expected to surface in onset position, e.g. $s i / \mathrm{Ng} /$-er $>$ si $[\mathrm{n}]$ er. Some mechanism appears to motivate uniformity in the outcome of underlying $/ \mathrm{Ng} /$ between the base sing and its derivative sing-er.

Paradigm uniformity (PU) effects such as this, which operate upon categorical phonological representations, can be incorporated into a modular architecture in various ways. Firstly, under a cyclic framework (Bermúdez-Otero 2011), the /g/-deletion rule is placed in the stem-level phonology and is therefore blind to the presence of the word-level suffix -er in sing-er. This has the effect of ordering suffixation after/g/-deletion in the morphophonological derivation. Secondly, a different approach posits the existence of output-output (OO-)correspondence constraints, which are violated in the event of a mismatch between morphologically related forms (Kenstowicz 1996; Benua 1997). If the appropriate OOcorrespondence constraint is ranked sufficiently high, then the non-uniformity in the pair si[n] $\sim * s i[\mathrm{ng}] e r$ will constitute a greater violation than the overapplication of /g/-deletion in si[y]er. Finally, one could avoid positing a phonological rule at all and instead place $/ \mathrm{y} /$ in the underlying lexical representation, but this approach fails to account for many aspects of the distribution of this sound in English.

It has been claimed that PU effects may be observed not only at the level of categorical phonology but also at the level of fine-grained phonetic detail. Since this would be an example of the phonetics displaying sensitivity to morphological structure, it has been used to argue for non-modular frameworks such as phonetic OO-correspondence (Steriade 2000) and Exemplar Theory (e.g. Winter \& Röttger 2011). I will now discuss two putative examples: the Withgott effect in American English and patterns of /1/-darkening and GOOSEfronting in Southern British English (see also Kawahara 2011: 2290-1). It will be shown that in cases such as these, which involve overt segmental affixation, it is often possible to account for apparent phonetic paradigm uniformity effects within a modular architecture by allowing prosodic structure to mediate between morphology and phonetics. One way to control for the effects of prosody is therefore to study morphological processes that do not involve overt segmental affixation.

2.3 The Withgott effect In American English, /t/ and /d/ are normally pronounced as a flap [ $\mathrm{r}]$ when they are (a) intervocalic and (b) not immediately followed by a stressed vowel within the same word, where "intervocalic" consonants include those preceded by /r/ and "stressed" vowels include those bearing either primary or secondary stress (see Kahn 1976: 91 ff.). However, misapplication of the flapping rule can be observed to occur in certain morphologically complex forms. For instance, as noted by Withgott (1982), speakers tend to produce a stop in mili $[\mathrm{t}] a r$-ist-ic, where a flap would be expected according to the above rule; meanwhile, the prosodically similar item càpi[r]al-ist-ic contains a flap. These two forms behave differently in spite of the fact that underlying / $t /$ appears to occur in the same segmental and prosodic environment in both. Instead, the realisation of $/ \mathrm{t} /$ in these forms shadows that found in the corresponding stems míli $[\mathrm{t}]$ àry and cápi $[\mathrm{r}] a l$, in which (non-)flapping applies transparently in accordance with the presence or absence of a following secondary stress. This is known as the Withgott effect.

Steriade (2000) argues that the failure of the /t/ to flap in mili $[\mathrm{t}]$ ar-ist-ic is driven by output-output correspondence constraints which penalise the occurrence of alternations within morphological paradigms. Crucially, Steriade (2000) also claims that flapping should be regarded as a phonetic process rather than a phonological one, meaning that the Withgott effect can be taken as an example of a phonetic paradigm uniformity effect. If output-output correspondence can operate not only at the level of categorical phonology but also at the level of fine-grained phonetic detail, then this poses a challenge to the modularity of the phonetics-phonology interface.

However, there are three problems with this analysis of the Withgott effect. First of all, Davis (2005) shows on the basis of monomorphemic forms such as Mèdi [t]erránean and Nàvra[t]ilóva - in which flapping fails to occur - that non-flapping is in fact the default in this prosodic position. This means that flapping does not underapply in mili it $] a r-i ́ s t-i c$, but rather overapplies in càpi[r]al-íst-ic. A second, more substantial, problem with Steriade's (2000) analysis is the claim that flapping should be taken to be a phonetic process rather than a phonological one, which is based on the assumption that flaps are characterised by a phonetic feature [extra-short closure]. It has been shown that American English flaps are articulatorily more than just 
extra-short stops (Derrick \& Gick 2011). Moreover, it turns out that flapping does show signs of categoricity, notably in the bimodal distribution of stop and flap allophones with respect to duration (Herd et al. 2010), and therefore it can be argued to be a phonological process. If it is phonological, then any paradigm uniformity effects that are observed to involve flapping do not present a challenge to modularity. ${ }^{1}$

The third and final problem with Steriade's (2000) analysis is the most important, since it highlights a common problem with claims of phonetic paradigm uniformity effects. It turns out that a modular architecture with sufficiently rich prosodic structure can successfully account for the Withgott effect, regardless of whether flapping is to be considered a phonological process or a phonetic one, by allowing prosody to mediate between morphology and phonetics. A cyclic derivation involving recursive foot structure can allow aspects of the prosodic structure of the stems mílitàry and cápital to be carried over into the derived forms militar-íst-ic and càpital-íst-ic, which can effectively grant the phonetics indirect access to morphological information (Jensen 2000; Davis 2005; Bermúdez-Otero \& McMahon 2006). In (1) are shown the derivations of militar-íst-ic and càpital-íst-ic from their respective stems (here and elsewhere, some irrelevant details of lower-level recursive foot structure are ignored).

a. mílitàry + -ist-ic $\rightarrow$ militar-íst-ic

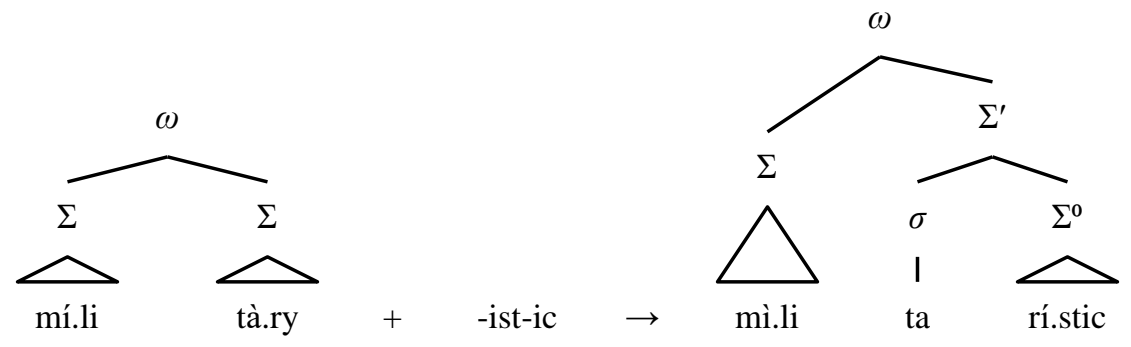

b. cápital + -ist-ic $\rightarrow$ càpital-íst-ic

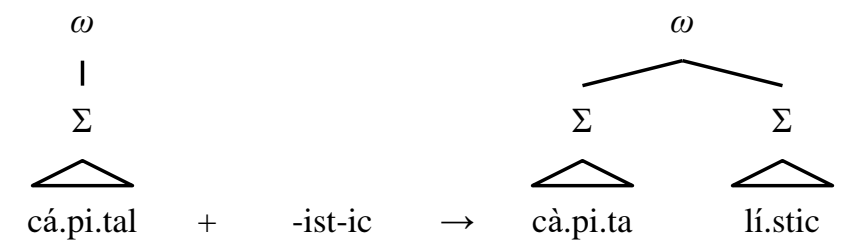

According to this analysis, faithfulness to the prosodic structure of the base form ensures that minimal disruption to the existing foot structure occurs when the suffix is attached. When added to a base, the suffix -ist-ic forms a trochaic foot of its own since it contains sufficient phonological material to meet the appropriate metrical constraints. When the suffix is attached to $[\omega[\Sigma$ mí.li $][\Sigma$ tà.ry $]$, the loss of the final vowel of the base and the resyllabification of preceding / $r$ / into the first syllable of the suffix (motivated by well-established constraints that disfavour hiatus and favour rightward syllabification of intervocalic consonants) reduce the second foot of the base to a single monomoraic syllable [ $\sigma$ ta ]. Foot-minimality constraints prevent this from continuing to form a foot on its own, and the stray syllable is instead recursively adjoined to the new foot formed by the suffix. On the other hand, when -ist-ic is adjoined to [ $\omega$ [ $\Sigma$ cá.pi.tal ] ], nothing prevents the foot structure of the base from remaining intact. Therefore, in spite of the fact that the third syllable bears no stress in either militar-ist-ic or càpital-íst-ic, it can be seen that its onset /t/ is footinitial (at some level of recursive foot structure) in the former but not the latter.

We can therefore re-state the prosodic conditioning of the flapping rule to require that /t/ (or /d/) not be initial in any foot projection. In mili $[\mathrm{t}]$ ar-ist-ic, /t/ is foot-initial and is therefore realised as a stop [t]; in càpi[r]al-íst-ic, /t/ is not foot-initial and is therefore realised as a flap [r]. Importantly, the rightward adjunction of the stray syllable produced during the derivation of mili[t]ar-ist-ic presupposes that this is the

${ }^{1}$ See Riehl (2003) for further criticism of Steriade's (2000) PU account of flapping. 
default treatment of stray syllables in such a prosodic environment - and this is supported by the absence of flapping in monomorphemic Mèdi[t]erránean, which can be assumed to bear a similar prosodic structure. Therefore it is possible to account for the Withgott effect in a modular architecture - even if flapping is counterfactually analysed as phonetically gradient - by allowing prosody to grant the phonetics indirect access to information about the morphological structure of a derived form.

2.4 /1/-darkening and GOOSE-fronting In Southern British English, as well as many other English dialects, /1/ occurs in both clear and dark allophones. Generally, clear [1] occurs in the syllable onset and dark [1] in the syllable coda. Both allophones contain a dorsal tongue gesture in addition to the apical gesture, but dark /1/ is characterised by greater magnitude and earlier timing of the former relative to the latter (Sproat \& Fujimura 1993). /1/-darkening interacts with another process, GoosE-fronting, which refers to the fronting of the vowel /u:/ that occurs in many varieties of English. In these varieties, this vowel approaches a central vowel [ $\mathrm{H}$ : except when followed by dark $/ 1 /$, in which case fronting fails to occur. A similar process also affects the FOOT vowel $/ \mho /$.

Strycharczuk \& Scobbie $(2016 ; 2017)$ investigate the manner in which these processes interact with morphological structure. As expected, words such as fool /fu:1/, in which /1/ is syllabified in the coda, are found to display a dark /1/ and an unfronted /u:/, while words such as húla /hu:lə/, in which /1/ is syllabified in the onset, display a clear /1/ and a fronted /u:/. However, morphologically complex forms such as fóol-ing /fu:l-Iy/ are found to display intermediate properties: generally, fóol-ing is found to have a slightly darker /1/ and a slightly less fronted /u:/ than húla, in spite of the fact that /l/ appears to be in the same prosodic environment in both. Crucially, in many cases the differences between fóol-ing and húla are too subtle to be attributed to distinct featural or segmental categories in the phonological surface representation, which suggests that this is a phonetic paradigm uniformity effect: it appears that the fine-grained phonetic detail of fóol-ing displays sensitivity to the presence of dark/1/ and back/u:/ in the corresponding stem fóol. Since this would be an example of the phonetics displaying sensitivity to the morphological relationships that exist between words, it again poses a challenge to the modularity of the phonetics-phonology interface.

Strycharczuk \& Scobbie (2017) favour an Exemplar Theoretic explanation for this phenomenon. According to Exemplar Theory, the lexicon is rich in phonetic detail. Instead of storing lexical items as sets of discrete phonological symbols, speakers build exemplar clouds which are updated every time they hear or produce a particular form. Importantly, inflected forms are stored wholesale along with all their fine-grained phonetic detail, and when retrieving an item from the lexicon a speaker activates not only the exemplar cloud of the required item but also those of any morphologically related items. This leads to phonetic paradigm uniformity effects, since the production of a form such as fóol-ing will be subtly influenced by simultaneous activation of the exemplar cloud of the morphologically related form fóol. Since Exemplar Theory rejects the distinction between categorical phonology and gradient phonetics, it is explicitly non-modular in nature.

However, this example again demonstrates how prosodic structure can be used to explain apparent phonetic paradigm uniformity effects within a modular architecture. The suffix -ing, like many English suffixes, never interferes with the stress and footing of the base and can thus be said to be adjoined directly to the prosodic word. As shown in (2), this results in morphologically complex forms such as fóol-ing bearing a different prosodic structure to superficially similar monomorphemic words such as húla.

a. fóol + -ing $\rightarrow$ fóol-ing

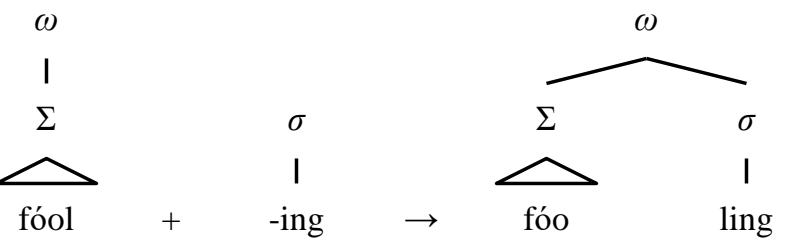

b. húla

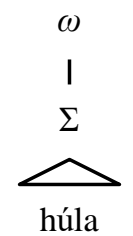

Since -ing does not interfere with the foot structure of the base fóol, the syllable it projects (including resyllabified stem-final /1/) is instead adjoined directly to the prosodic word. In contrast, the final syllable of húla is not a suffix and is thus fully footed along with the rest of the word. It can therefore be seen that the 
/1/ of fóol-ing and the /1/ of húla occupy different positions in prosodic structure: the former occupies the onset of an unfooted syllable, and the latter occupies the onset of a syllable in non-initial position within a foot. Additionally, /l/ stands in a different prosodic relation to the preceding /u:/. Although this representation may not necessarily predict that the /1/ of fóol-ing will be slightly darker than the /1/ of húla, it is well-known that different prosodic structures may bring about subtle differences in articulation (Gussenhoven \& Rietveld 1992; Cho \& Keating 2001; Sugahara \& Turk 2009). As a result, it cannot be claimed that patterns of /1/darkening and GOOSE-fronting in Southern British English display phonetic paradigm uniformity effects.

Having highlighted a confound between morphology and prosody in some previous arguments for phonetic paradigm uniformity effects, I will now turn my attention to Scottish Gaelic, where that confound can be avoided owing to the existence of morphological processes that do not involve overt segmental affixation.

\section{Scottish Gaelic}

3.1 Lenition One of the most striking characteristics of all the Celtic languages alive today is their initial mutations, which are complex series of alternations affecting the left edge of the word. Under the lenition mutation in Scottish Gaelic, radical initial consonants alternate with their lenited counterparts. Depending on the consonant being lenited, lenition may involve such processes as frication, debuccalisation or even deletion. A sample of the alternations that occur under lenition is shown in Table 1.

\begin{tabular}{|c|c|c|c|c|c|c|c|c|c|}
\hline Radical & $\mathrm{p}$ & $\mathrm{p}^{\mathrm{h}}$ & $\mathrm{t}$ & $\mathrm{t}^{\mathrm{h}}$ & $\mathrm{k}$ & $\mathrm{k}^{\mathrm{h}}$ & $\mathrm{f}$ & $\mathrm{s}$ & $\mathrm{m}$ \\
\hline Lenited & $\mathrm{v}$ & $\mathrm{f}$ & $\mathrm{\gamma}$ & $\mathrm{h}$ & $\mathrm{\gamma}$ & $\mathrm{x}$ & $\varnothing$ & $\mathrm{h}$ & $\mathrm{v}$ \\
\hline
\end{tabular}

Table 1: A sample of the alternations that occur under lenition.

Lenition may occur with no immediately adjacent overt trigger, indicating that lenition must fall under the domain of morphosyntax and should be thought of as a form of inflection. For example, the lenition of [p] to [v] in all attributive adjectives following the feminine noun caileag 'girl' in (3) can be taken to represent morphological agreement. Lenition is indicated orthographically by insertion of a following $\langle\mathrm{h}\rangle$.

$$
\begin{aligned}
& \text { balach beag bàn caileag bheag bhàn } \\
& \text { [palıəx prk pa:n] [ [k thalak vrk va:n] } \\
& \text { boy small.MASC fair_haired.MASC girl small.FEM fair_haired.FEM } \\
& \text { 'small fair-haired boy' 'small fair-haired girl' }
\end{aligned}
$$

Due to the complex nature of some of the alternations that take place under the Celtic initial mutations, the precise mechanism by which they occur is a subject of debate. Some authors incorporate mutations into a strictly concatenative theory of morphology by invoking the affixation of subsegmental phonological material (Wolf 2007; Iosad 2014), while others use it as evidence for the existence of morphological processes that involve the phonologically arbitrary substitution of one segment for another (Green 2006; 2007; Hannahs 2013). Either way, radical and lenited forms of a given lexical item can be regarded as members of the same inflectional paradigm.

3.2 Vowel nasalisation Scottish Gaelic stressed vowels can display contrastive nasalisation, although minimal pairs are rare. In some environments nasalisation is highly predictable: for instance, vowels are normally strongly nasalised when they occur after initial [m], e.g. madainn [mãtonn]] 'morning', although unpredictable exceptions occur in which this is blocked, e.g. marag [marak] 'pudding'. However, even when this full nasalisation fails to occur, it is possible that a small amount of co-articulatory partial nasalisation is always present on the following vowel. While the full nasalisation in words such as madainn [mãtonn] is (at least marginally) contrastive and must therefore be assumed to be present in the discrete phonological surface representation, I claim that any partial nasalisation found in marag [marak] is purely phonetic in nature.

In words of the type madainn [mãtən ${ }^{j}$ ], in which full nasalisation occurs after [m], full nasalisation also occurs after corresponding [v] in the lenited form mhadainn [vãtən n] ${ }^{j}$. Since this kind of nasalisation must be 
phonological, its overapplication in lenited forms does not pose any challenge to modularity and can be handled in various ways. If we assume that it is triggered by a default phonological rule that spreads [+nasal] from $[\mathrm{m}]$ onto the following vowel (subject to lexically specific blocking), then its overapplication in lenited forms can be explained cyclically by placing this rule in the stem-level phonology. Alternatively, the overapplication can be explained using OO-correspondence constraints that penalise any alternation between nasal and non-nasal vowels at the level of categorical phonological representations. Finally, one could simply assume that no synchronic phonological spreading process is involved at all and that this nasalisation is purely lexical, although this approach fails to capture generalisations that can be made about the distribution of nasalisation such as its prevalence after initial [m]. Either way, as long as full nasalisation exists in the discrete surface phonological representation then its overapplication in lenited forms can be handled without difficulty in a modular architecture and is of no particular interest to us here. ${ }^{2}$

However, if any partial nasalisation found in words such as marag [marak] is taken to be phonetic in nature, then a modular architecture predicts that no trace of this nasalisation may be found in the corresponding lenited form mharag [varak]. This is because the phonetics is predicted to be completely blind to the fact that a morphological relationship exists between these two forms. Any trace of nasalisation detected in the lenited forms of words of this type would instead support non-modular frameworks that allow phonetic paradigm uniformity effects, such as phonetic OO-correspondence or Exemplar Theory.

In this study I use nasal airflow data to investigate phonological and phonetic patterns of nasalisation after initial [m] and test the predictions of the modular architecture. It is predicted that a clear distinction will be found between these two types of nasalisation and that, while phonological nasalisation may display apparent paradigm uniformity effects, phonetic nasalisation will not.

\section{Methods}

4.1 Data collection Nasal airflow data was collected from one 62-year-old male native speaker of Scottish Gaelic from Ness, Isle of Lewis. Although this speaker spent much of his adult life living on the Scottish mainland, where he did not use Scottish Gaelic on a regular basis, by the time of recording he had once again been living in Ness for a number of years and spoke the language daily.

A word-list was compiled containing 42 Scottish Gaelic words or short phrases. All contained stressed /a/, either fully nasalised or not, in a variety of positions. Since it has long been known that the degree of nasal airflow in nasalised vowels can correlate positively with vowel height via the impedance effect (House \& Stevens 1956), it was decided that the quality of the vowel should remain constant. /a/ was chosen out of convenience, since it appears to occur with greater lexical frequency than any other vowel in Scottish Gaelic. ${ }^{3}$

Twelve different randomisations of the word-list were created. No distractors were placed among the stimuli, as this would greatly decrease the efficiency of the data-collection process: it is not thought that the selection of stimuli presented to the speaker could realistically have revealed any more about the purpose of the experiment than could already have been inferred from the presence of the nasal airflow mask. However, this paper will focus on only six of the stimuli.

Recording was carried out using the PCquirer X16 multi-channel data acquisition system produced by Scicon R\&D Inc. The setup includes an oral mask mounted directly on a transducer containing a built-in microphone, and a nasal mask which is attached to the transducer by a flexible plastic tube. The transducer passes audio, oral airflow and nasal airflow data in three channels to the X16 system, which is in turn connected to a computer via a USB port. Recording can be carried out in clips of maximum length $10 \mathrm{~s}$. Although both oral and nasal airflow were recorded, only nasal airflow will be referred to in this paper.

Before each recording session, the nasal mask was tightly fitted to the speaker using straps passed around the back of the head. While recording, the speaker held the transducer firmly in his hand such that the attached oral mask fitted comfortably around the mouth. For each stimulus in turn, a 10-s clip was recorded in which

\footnotetext{
${ }^{2}$ I will use the term phonological nasalisation to refer to nasalisation that is present in the discrete phonological surface representation, without necessarily committing to an analysis in which it is phonologically derived rather than lexical.

${ }^{3}$ It has also long been observed (Ohala 1971) that supposedly non-nasal low vowels may spontaneously display low levels of nasal airflow due to mechanical coupling between the velum and the tongue root. However, this potential problem was deemed to be outweighed by the difficulty inherent in finding a sufficient number of suitable lexical items without low vowels, and in any case this phenomenon was ultimately not observed in the data.
} 
the speaker read aloud the given word or phrase inside the carrier sentence ' $S e_{-}$a chanas mi [ $\int_{-}{ }_{-} \partial$ xanəs mi] 'I will say _' three times. In total, twelve recording sessions were carried out using all twelve randomisations of the word-list. This yielded 36 tokens of each stimulus, less a handful that were unusable due to speech errors or unclear articulation.

4.2 Data analysis Each token was segmented manually in Praat using the audio channel, in order to identify the start and end points of the target vowel, the preceding consonant and the following consonant. Boundaries between consonants and vowels were identified by means of the increase/decrease in acoustic intensity and/or the onset/offset of clear formant structure.

Visual inspection revealed the presence of a small lag, on the order of around $15 \mathrm{~ms}$, in the nasal airflow channel relative to the audio channel. For instance, the sudden decrease in nasal airflow accompanying the release of a nasal consonant - an inevitable consequence of the reduction in oral pressure - could be seen to occur a short time later than the sudden increase in acoustic intensity observed in the audio channel. It was also found that the start of the closure of an oral stop following a strongly nasalised vowel was often accompanied by a short, sharp spike in nasal airflow, presumably resulting from slight mis-timing of the velic closure relative the oral closure: if the velum is not yet fully closed at the moment that full oral closure is achieved then the sudden increase in oral pressure will momentarily force air into the nasal cavity, resulting in the observed spike. Since this spike in the nasal channel provides a local maximum whose position in time can be precisely determined, and since it can be related to a well-defined point in the audio channel (the onset of silence corresponding to oral closure), it provides a way of calculating the lag in the nasal channel relative to the audio channel. By extracting values for nasal airflow at $1 \mathrm{~ms}$ intervals near the start of the [t] in madainn [mãtəñ]'] 'morning', and averaging across all tokens, it was found that the spike in nasal airflow occurred 14 ms after the onset of silence (to the nearest ms). Based on the assumption that this spike is in reality simultaneous with the start of the oral closure, a corresponding 14-ms correction was applied to all of the nasal airflow data.

Visual inspection also revealed that the true baseline in the nasal airflow channel was offset slightly from zero, and that the magnitude and direction of this offset varied slightly between recording sessions. For each recording session, the true baseline was determined by calculating the average degree of nasal airflow in the middle of all initial oral stops, where nasal airflow is expected in reality to be exactly zero. Initial stops were used, rather than medial or final stops, because they are longer in duration and more strongly articulated, thus reducing the possibility of any nasal airflow "leaking" into the closure period from adjacent segments. This value was then subtracted from all data points in the nasal airflow channel for each recording session.

Because it was not possible to form an absolutely perfect seal around the nasal mask, some small amount of leakage was inevitable. The degree of leakage could be expected to vary between recording sessions as a result of slight differences in the position and tightness of the mask each time it was fitted. As a result, it is possible that tokens from some sessions may show a slightly greater amount of nasal airflow overall than tokens from other sessions simply due to lesser amounts of leakage. When comparing average nasal airflow across different stimuli, it is therefore important that if a given session $S$ contributes $n$ tokens of one particular stimulus to the data set then session $S$ must contribute exactly $n$ tokens of each other stimulus. Because a small proportion of tokens proved unusable, it was necessary to omit a number of other tokens in order to create a fully comparable data set for the six stimuli that will be discussed here. Ultimately, 27 tokens of each stimulus were used.

In order to analyse the data, values for nasal airflow were extracted at one-eighth intervals throughout the duration of each segment in the CVC sequence consisting of the target vowel, the preceding consonant and the following consonant. Including endpoints, this resulted in 25 data points per token. By averaging across all tokens of each stimulus, dynamic nasal airflow profiles were produced showing nasal airflow values against normalised time for each CVC sequence. For each token, single values were also calculated for the degree of nasalisation early in the vowel (by taking the average of the three data points contained entirely within the first half of the vowel) and late in the vowel (by taking the average of the three data points contained entirely within the second half of the vowel). For simplicity, all values for nasal airflow are expressed in terms of the channel voltage in millivolts $(\mathrm{mV})$ as output by the $\mathrm{X} 16$ system; this measure was found to display a very nearly linear relationship with flow rate as expressed in units of volume against time. 


\section{Results and discussion}

5.1 Dynamic nasal airflow profiles The six stimuli that will be discussed here are shown in Table 2, with the relevant CVC sequence underlined. They consist of three lexical items, each occurring in both indefinite and definite form. As discussed in §3.2, madainn [mãtən ]] 'morning' displays full nasalisation after initial [m] while marag [marak] 'pudding' does not. In $a^{\prime}$ mhadainn [ə vãañn] 'the morning' and $a^{\prime}$ mharag [ə varak] 'the pudding', lenition occurs as a result of the presence of the feminine definite article. Also included for comparison are badan [patan] 'thicket', in which no nasalisation occurs, and am badan [o matan] 'the thicket', in which a phonological process assimilates [p] to the final nasal of the masculine definite article ( $\leftarrow$ /əm patan/). For simplicity, the six stimuli will henceforth be referred to by orthographic form only.

\begin{tabular}{|c|c|c|c|c|c|}
\hline \multicolumn{3}{|c|}{ Indefinite } & \multicolumn{3}{c|}{ Definite } \\
\hline madainn & {$\left[\right.$ mãtən $\left.{ }^{j}\right]$} & 'morning' & $a^{\prime}$ mhadainn & [ə vãtəñ $]$ & 'the morning' \\
\hline marag & {$[$ marak] } & 'pudding' & $a^{\prime}$ mharag & [ə varak] & 'the pudding' \\
\hline badan & [patan] & 'thicket' & am badan & [ə matan] & 'the thicket' \\
\hline
\end{tabular}

Table 2: The six stimuli that will be discussed in this study.

Since the full nasalisation found in the vowels of madainn and $a^{\prime}$ mhadainn is claimed to be phonological, it is predicted to display categoricity, i.e. to be relatively strong and to be maintained throughout the duration of the vowel, resulting in a plateau-like profile. On the other hand, any partial nasalisation present in the vowel of marag is claimed to be phonetic in nature and so is predicted to display gradience, i.e. to be weaker and to occur only early in the vowel, resulting in a cline-like profile; meanwhile, the vowel of $a^{\prime}$ mharag is predicted to display no nasalisation at all. Likewise, the vowel of badan is also predicted to display no nasalisation; finally, the vowel of am badan is predicted to display the same cline-like profile as that of marag since under a modular architecture the phonetics should be blind to the fact that the preceding nasal is phonologically derived.

Dynamic nasal airflow profiles for the relevant CVC sequence from each of the six stimuli are shown in Fig. 1. As far as visual inspection can tell, the above predictions appear to be confirmed: the vowels of madainn and $a^{\prime}$ mhadainn display a plateau-like pattern of strong nasal airflow throughout the duration of the vowel; those of marag and am badan display a cline-like pattern of weaker, rapidly decreasing nasal airflow early in the vowel; and those of $a^{\prime}$ mharag and badan both display no nasalisation at all throughout the duration of the vowel. ${ }^{4,5}$

These observations are in line with a modular analysis in which (i) the vowels of madainn and $a^{\prime}$ mhadainn carry (categorical) phonological nasalisation while those of the other items do not; (ii) (gradient) phonetic nasalisation occurs across the board in vowels preceded by [m]; and (iii) phonological nasalisation may be subject to paradigm uniformity effects but phonetic nasalisation may not. In Table 3, the six stimuli are classified according to the type(s) of nasalisation I claim they show.

5.2 Degree of nasalisation early and late in the vowel Given that (categorical) phonological nasalisation should affect the entire duration of the vowel while (gradient) phonetic nasalisation should affect only the early part of the vowel, it should be possible to quantitatively distinguish between these two types of nasalisation by separately investigating nasal airflow early in the vowel and late in the vowel. For each token, separate values for the degree of nasalisation early in the vowel and late in the vowel were calculated as described in §4.2. If two stimuli differ from one another w.r.t. the presence or absence of phonological nasalisation then they are predicted to display different levels of nasal airflow to one another both early in

\footnotetext{
${ }^{4}$ Note the sharp spike in nasal airflow, discussed in $\S 4.2$, that appears at the beginning of the stop closure in madainn and $a^{\prime}$ mhadainn ( 2 in normalised time).

${ }^{5}$ A considerable amount of nasal airflow appears to be present during the fricative [v] preceding the target vowel in $a^{\prime}$ mhadainn. The simplest explanation for this is that it is purely phonetic co-articulatory nasalisation caused by the following strongly nasalised vowel; the fact that nasal airflow is even greater during the fricative than during the vowel itself can be explained by the presence of an oral constriction in the former. $C f$. Warner et al. (2015), who find nasalisation to occur during fricatives only rarely in Scottish Gaelic.
} 


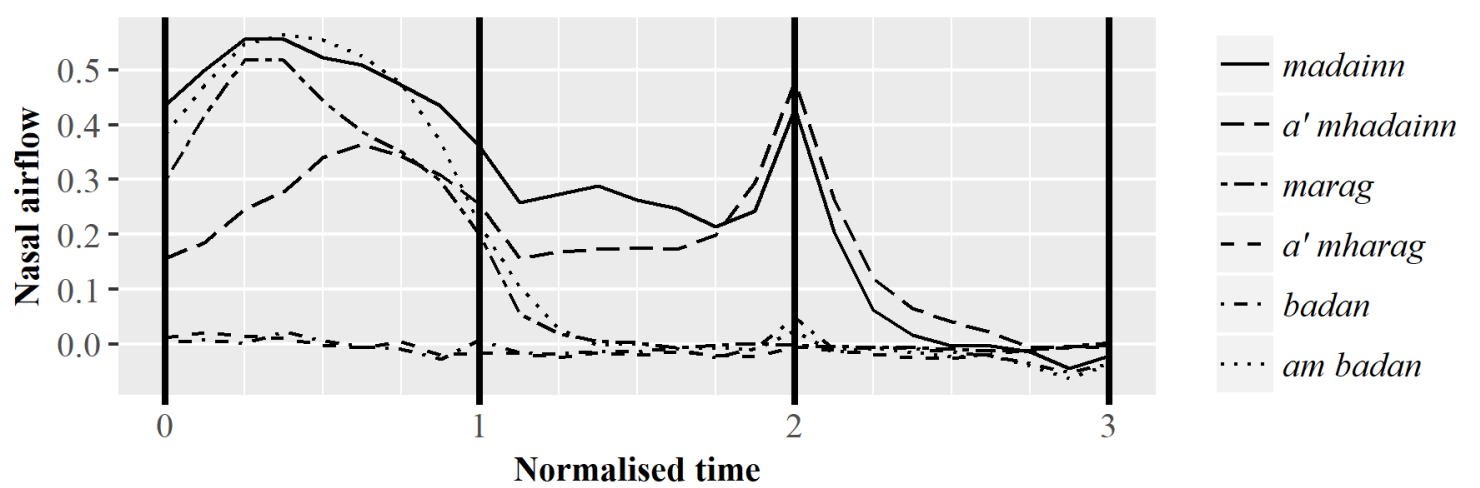

Fig. 1 (above): Dynamic nasal airflow profiles for the relevant CVC sequence from each of the six stimuli. The values on the $\mathrm{x}$-axis represent normalised time, where $0-1$ is the duration of the consonant preceding the target vowel, 1-2 is the duration of the target vowel, and 2-3 is the duration of the consonant following the target vowel.

\begin{tabular}{|c|c|c|}
\cline { 3 - 3 } \multicolumn{1}{c|}{} & Phonological nasalisation? & Phonetic nasalisation? \\
\hline madainn [mãt] & \multirow{2}{*}{ yes } & yes \\
\hline$a^{\prime}$ mhadainn [vãt] & & no \\
\hline marag [mar] & \multirow{3}{*}{ no } & yes \\
\hline$a^{\prime}$ mharag [var] & & no \\
\hline badan [pat] & & no \\
\hline am badan [mat] & & yes \\
\hline
\end{tabular}

Table 3: The six stimuli classified according to the type(s) of nasalisation I claim they show.

the vowel and late in the vowel; if they differ from one another only w.r.t. the presence of absence of phonetic nasalisation then they are predicted to display different levels of nasal airflow to one another early in the vowel but not late in the vowel.

Fig. 2 shows the degree of nasalisation for all six stimuli both early in the vowel and late in the vowel, and Table 4 shows the results of unpaired $t$-tests on all 15 logically possible pairwise comparisons between the six stimuli both early in the vowel and late in the vowel. In Table 4, degrees of statistical significance are shown after Bonferroni correction for multiple comparisons, which is performed by multiplying each $p$-value by the total number of comparisons made (i.e. 30). It can be seen that the above predictions are borne out in every single case: early in the vowel, any two given stimuli display significantly different degrees of nasalisation iff they differ from one another w.r.t. the presence or absence of phonological and/or phonetic nasalisation; late in the vowel, any two given stimuli display significantly different degrees of nasalisation iff they differ from one another w.r.t. the presence or absence of phonological nasalisation. Note that, early in the vowel, a difference is even captured between madainn and $a^{\prime}$ mhadainn, which both carry phonological nasalisation but which differ w.r.t. the presence of absence of an additional layer of phonetic nasalisation. Importantly, no statistically significant difference exists between the vowels of $a^{\prime}$ mharag and badan in spite of the fact that the former shares a morphological paradigm with marag, and no statistically significant difference exists between those of marag and am badan in spite of the fact that the preceding nasal in the latter is phonologically derived. ${ }^{6}$

\subsection{Discussion These results support a modular architecture in which a distinction is made between}

\footnotetext{
${ }^{6}$ It could potentially be objected that Bonferroni correction is excessively conservative and that it might here be masking the presence of some otherwise statistically significant differences. However, only in one case did Bonferroni correction cause a previously significant difference to become non-significant: the difference between marag and $a^{\prime}$ mharag late in the vowel was marginally significant $(p=0.0412)$ before correction but non-significant after.
} 


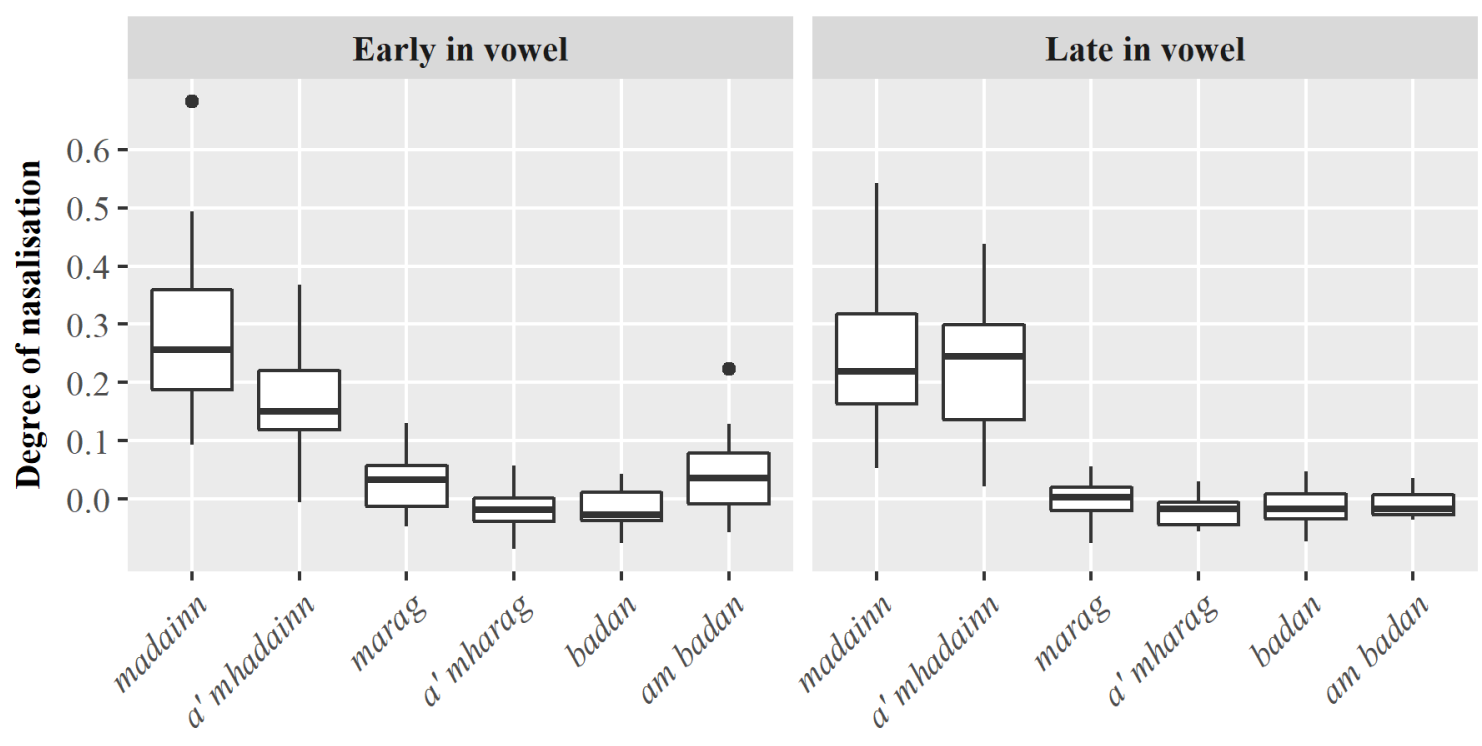

Fig. 2 (above): Degree of nasalisation for all six stimuli both early in the vowel and late in the vowel.

\begin{tabular}{|c|c|c|c|c|c|c|c|c|c|c|c|c|}
\hline & \multicolumn{6}{|c|}{ Early in vowel } & \multicolumn{6}{|c|}{ Late in vowel } \\
\hline & 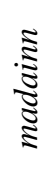 & 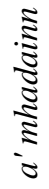 & $\begin{array}{l}\infty \\
\vdots \\
\vdots \\
\vdots\end{array}$ & 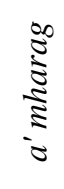 & 点 & 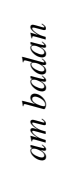 & 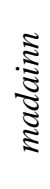 & 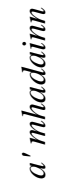 & 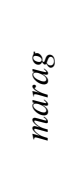 & $\frac{\infty}{\vdots}$ & $\tilde{\Xi}$ & $\begin{array}{l}\tilde{\Xi} \\
\mathbb{\Xi} \\
\Xi \\
\Xi\end{array}$ \\
\hline madainn & & $*$ & $* * *$ & $* * *$ & $* * *$ & $* * *$ & & n.s. & $* * *$ & $* * *$ & $* * *$ & $* * *$ \\
\hline$a^{\prime}$ mhadainn & & & $* * *$ & $* * *$ & $* * *$ & $* * *$ & & & $* * *$ & $* * *$ & $* * *$ & $* * *$ \\
\hline marag & & & & $* *$ & $* *$ & n.s. & & & & n.s. & n.s. & n.s. \\
\hline$a^{\prime}$ mharag & & & & & n.s & $* *$ & & & & & n.s. & n.s. \\
\hline badan & & & & & & $* *$ & & & & & & n.s. \\
\hline am badan & & & & & & & & & & & & \\
\hline
\end{tabular}

Table 4: Results of unpaired t-tests on all 15 logically possible pairwise comparisons between the six stimuli both early in the vowel and late in the vowel. Asterisks denote degrees of statistical significance after Bonferroni correction: *** denotes $\mathrm{p} \times 30<0.001$; otherwise $* *$ denotes $\mathrm{p} \times 30<0.01$; otherwise * denotes $\mathrm{p} \times 30<0.05$; otherwise $\mathrm{n}$.s. denotes not significant.

phonological and phonetic vowel nasalisation. Phonological nasalisation is categorical, and thus manifests itself as strong nasalisation throughout the duration of the vowel, while phonetic nasalisation is gradient, and thus manifests itself as weaker nasalisation restricted to the early part of the vowel. In items such as madainn, which display phonological nasalisation, this nasalisation also occurs in the lenited form $\left(a^{\prime}\right)$ mhadainn, and this is fully compatible with a modular architecture. However, in items such as marag, which display only phonetic nasalisation, no nasalisation at all occurs in the lenited form $\left(a^{\prime}\right)$ mharag, in line with the prediction that the phonetics is blind to morphological relationships.

Of course, it does not follow from the lack of phonetic PU effects observed here that such effects cannot occur. However, the clear distinction between phonological and phonetic varieties of nasalisation demonstrated here, both in terms of their realisation and their (non-)susceptibility to morphological conditioning, is exactly in line with the predictions of a modular architecture. If a non-modular mechanism lies behind putative phonetic PU effects in other languages, why do we not see such effects here? Under phonetic OO-correspondence, where phonetic PU effects derive from the existence of phonetic OOconstraints, it could ultimately be claimed that the relevant constraints must simply be ranked low in Scottish 
Gaelic. A negative result is more challenging for Exemplar Theory, according to which phonetic PU effects emerge mechanically from exemplar dynamics and should therefore occur universally wherever they are predicted to be possible. Although these effects, where they are claimed to exist, are small, their failure to emerge here comes in spite of considerable statistical power - even subtle differences were captured without difficulty wherever this was compatible with the predictions of a modular architecture.

This negative result adds to the challenges faced by Exemplar Theory. For example, exemplar-theoretic explanations have been put forward to account for incomplete neutralisation in final devoicing (Ernestus \& Baayen 2006; 2007; Winter \& Röttger 2011), which is not readily accommodated in modular architectures even with the intervention of prosody $(c f . \S 2)$. However, exemplar-theoretic explanations incur problems of their own: for instance, they have difficulty accounting for the fact that incomplete neutralisation occurs even in nonce words presented orthographically, which have no exemplar cloud of their own (e.g. Ernestus \& Baayen 2006), and in non-alternating items with orthographically voiced final consonants, which do not share a morphological paradigm with voiced forms (e.g. Port \& O'Dell 1985). Additionally, Ernestus \& Baayen (2007) predict that the process should display symmetry: if suffixed forms with voiced stem-final consonants are responsible for incomplete final devoicing of unsuffixed forms in the same paradigm, then the existence of devoiced forms should likewise lead to slight devoicing of voiced forms in the paradigm. Kaplan (2017) sets out to test this prediction, and finds it to be false.

\section{Conclusion}

This study searched for evidence of phonetic PU effects in vowel nasalisation in Scottish Gaelic. The results strongly support a modular architecture of grammar, in which a distinction is maintained between categorical phonological and gradient phonetic vowel nasalisation. It was shown that phonological nasalisation may be subject to PU effects while phonetic nasalisation may not, in line with the predictions of a modular architecture. A modular explanation was also offered for some putative examples of phonetic PU effects in English, by allowing prosodic structure to mediate between morphology and phonetics and thus grant the phonetics indirect access to information about morphological structure. While this study does not prove that phonetic PU effects cannot occur, it raises the question of why they are not found here and suggests that non-modular frameworks may not provide the correct explanation for other putative phonetic PU effects in the languages of the world.

\section{References}

Benua, Laura. 1997. Transderivational identity: phonological relations between words. PhD dissertation, University of Massachusetts Amherst.

Bermúdez-Otero, Ricardo. 2011. Cyclicity. In Marc van Oostendorp, Colin J. Ewen, Elizabeth Hume \& Keren Rice (eds.), The Blackwell Companion to Phonology 4: Phonological Interfaces, 2019-48. Oxford: Blackwell.

Bermúdez-Otero, Ricardo \& April McMahon. 2006. English phonology and morphology. In Bas Aarts \& April McMahon (eds.), The Handbook of English Linguistics, 382-410. Oxford: Blackwell.

Bermúdez-Otero, Ricardo \& Graeme Trousdale. 2012. Cycles and continua: on unidirectionality and gradualness in language change. In Terttu Nevalainen \& Elizabeth Closs Traugott (eds.), The Oxford Handbook of the History of English, 691-720. New York: Oxford University Press.

Cho, Taehong \& Patricia A. Keating. 2001. Articulatory and acoustic studies on domain-initial strengthening in Korean. Journal of Phonetics 29(2), 155-90.

Cohn, Abigail C. 1990. Phonetic and phonological rules of nasalization. UCLA Working Papers in Phonetics 76.

Davis, Stuart. 2005. Capitalistic vs. militaristic: the paradigm uniformity effect reconsidered. In Laura Downing, T. Alan Hall \& Renate Raffelsiefen (eds.), Paradigms in Phonological Theory, 106-21. Oxford: Oxford University Press.

Derrick, Donald \& Bryan Gick. 2011. Individual variation in English flaps and taps: a case of categorical phonetics. Canadian Journal of Linguistics 56(3), 307-19.

Ernestus, Mirjam \& R. Harald Baayen. 2006. The functionality of incomplete neutralization in Dutch: the case of pasttense formation. In Louis Goldstein, D. H. Whalen \& Catherine T. Best (eds.), Laboratory Phonology 8 (Phonology and Phonetics 4-2), 27-49. Berlin: Mouton de Gruyter.

Ernestus, Mirjam \& R. Harald Baayen. 2007. Intraparadigmatic effects on the perception of voice. In Jeroen van de Weijer \& Erik Jan van der Torre (eds.), Voicing in Dutch: (De)voicing - phonology, phonetics, and psycholinguistics (Current Issues in Linguistic Theory 286), 153-74. Amsterdam: Benjamins.

Green, Anthony D. 2006. The independence of phonology and morphology: The Celtic mutations. Lingua 116(11), 1946- 
85.

Green, Anthony D. 2007. Phonology Limited (Linguistics in Potsdam 27). Potsdam: Universitätsverlag.

Gussenhoven, C. \& A. C. M. Rietveld. 1992. Intonation contours, prosodic structure and preboundary lengthening. Journal of Phonetics 20, 283-303.

Hannahs, S. J. 2013. Celtic initial mutation: pattern extraction and subcategorisation. Word Structure 6(1), 1-20.

Herd, Wendy, Allard Jongman \& Joan Sereno. 2010. An acoustic and perceptual analysis of /t/ and /d/ flaps in American English. Journal of Phonetics 38(4), 504-16.

House, Arthur S. \& Kenneth N. Stevens. 1956. Analog studies of the nasalization of vowels. Journal of Speech and Hearing Disorders 21, 218-32.

Iosad, Pavel. 2014. The phonology and morphosyntax of Breton mutation. Lingue e Linguaggio 13(1), 23-42.

Jensen, John T. 2000. Against ambisyllabicity. Phonology 17, 187-235.

Kahn, Daniel. 1976. Syllable-based generalizations in English phonology. PhD dissertation, MIT.

Kaplan, Abby. 2017. Incomplete neutralization and the (a)symmetry of paradigm uniformity. In Aaron Kaplan, Abby Kaplan, Miranda K. McCarvel \& Edward J. Rubin (eds.), Proceedings of the 34th West Coast Conference on Formal Linguistics, 319-28. Somerville, MA: Cascadilla Proceedings Project.

Kawahara, Shigeto. 2011. Experimental approaches in theoretical phonology. In Marc van Oostendorp, Colin J. Ewen, Elizabeth Hume \& Keren Rice (eds.), The Blackwell Companion to Phonology 4: Phonological Interfaces, 2283303. Oxford: Blackwell.

Keating, Patricia A. 1996. The phonology-phonetics interface. In Ursula Kleinhenz (ed.), Interfaces in Phonology (Studia Grammatica 41), 262-78. Berlin: Akademie Verlag.

Kenstowicz, Michael. 1996. Base-identity and uniform exponence: alternatives to cyclicity. In Jacques Durand \& Bernard Laks (eds.), Currents Trends in Phonology: Models and Methods 1, 363-93. Salford: European Studies Research Institute, University of Salford.

Ohala, John J. 1971. Monitoring soft palate movements in speech. The Journal of the Acoustical Society of America 50, 140.

Pierrehumbert, Janet B. 2002. Word-specific phonetics. In Carlos Gussenhoven \& Natasha Warner (eds.), Laboratory Phonology 7 (Phonology and Phonetics 4-1), 101-39. Berlin: Mouton de Gruyter.

Port, Robert \& Michael O'Dell. 1985. Neutralization of syllable-final voicing in German. Journal of Phonetics 13, 45571.

Riehl, Anastasia K. 2003. American English flapping: perceptual and acoustic evidence against paradigm uniformity with phonetic features. Working Papers of the Cornell Phonetics Laboratory 15(271-337).

Scobbie, James M. 2005. The phonetics-phonology overlap. QMUC Speech Science Research Centre Working Paper WP-1.

Sproat, Richard \& Osamu Fujimura. 1993. Allophonic variation in English /l/ and its implications for phonetic implementation. Journal of Phonetics 21, 291-311.

Steriade, Donca. 2000. Paradigm uniformity and the phonetics-phonology boundary. In Michael B. Broe \& Janet B. Pierrehumbert (eds.), Papers In Laboratory Phonology V: Acquisition and the Lexicon, 313-34. Cambridge: Cambridge University Press.

Strycharczuk, Patrycja \& James M. Scobbie. 2016. Gradual or abrupt? The phonetic path to morphologisation. Journal of Phonetics 59, 76-91.

Strycharczuk, Patrycja \& James M. Scobbie. 2017. Whence the fuzziness? Morphological effects in interacting sound changes in Southern British English. Laboratory Phonology 8(1), 1-21.

Sugahara, Mariko \& Alice Turk. 2009. Durational correlates of English sublexical constituent structure. Phonology 26(3), 477-524.

Warner, Natasha, Daniel Brenner, Jessamyn Schertz, Andrew Carnie, Muriel Fisher \& Michael Hammond. 2015. The aerodynamic puzzle of nasalized fricatives: Aerodynamic and perceptual evidence from Scottish Gaelic. Laboratory Phonology 6(2), 197-241.

Winter, Bodo \& Timo Röttger. 2011. The nature of incomplete neutralization in German: Implications for laboratory phonology. Grazer Linguistische Studien 76, 55-74.

Withgott, Mary Margaret. 1982. Segmental evidence for phonological constituents. PhD dissertation, University of Texas, Austin.

Wolf, Matthew. 2007. For an autosegmental theory of mutation. In Leah Bateman, Michael O'Keefe, Ehren Reilly \& Adam Werle (eds.), Papers in Optimality Theory III (University of Massachusetts Occasional Papers in Linguistics 32), 315-404. Amherst, MA: GLSA. 